\title{
Peran Gender dalam Hubungan Seks pada Wanita Hamil
}

\author{
Budi Astyandini $^{{ }^{*}}$, Khobibah ${ }^{2,}$ Mimi Ruspita $^{3}$ \\ ${ }_{1,2,3}$ UPP Poltekkes Kemenkes Semarang Kampus Kendal \\ *Email: asty.budi@yahoo.com
}

\begin{abstract}
Background: sexual intercourse during pregnancy is a physiological need for pregnant women that is influenced by factors of perception from within oneself and previous experience and gender role factors in the family. Aim of this study is to knowing the relationship between gender roles and sexual relations in pregnant women. Methods: Non-experimental research with a population of all pregnant women in the village of Curugsewu in the District of Patean. The total sample of pregnant women receiving antenatal care was 30 with the Kendal statistical test. Results: result of statistic shows significance $T=0.022$ $<0.005$. There is a relationship between gender roles and sexual relations of sufficient strength in the negative direction -391*.Conclusion: there is a relationship between gender roles and sexual relations, the husband's role is very dominant but the frequency of sex in early pregnancy is largely not done because it is influenced by cultural factors and a history of previous abortion sex.
\end{abstract}

Keywords: abortion, gender, pregnancy, sex

\section{PENDAHULUAN}

Kehamilan merupakan suatu proses reproduksi dari wanita yang merupakan bukti dari keberhasilan sistem reproduksi. Kehamilan normal berlangsung dalam 3 trimester yang terdiri dari 280 hari atau 40 minggu (Pudiastuti, 2012). Berdasarkan data dari WHO didapatkan angka kematian ibu pada tahun 2014 di dunia terdapat 298.000 jiwa. Indonesia merupakan negara dengan angka kematian ibu yang masih tinggi berbagai upaya dilakukan pemerintah untuk menurunkan angka kematian ibu ditargetkan pada tahun 2019 adalah sebesar 309/100.000. Berbagai penyebab kematian ibu sebagian besar dapat dicegah dengan pengelolaan dan pemenuhuan kebutuhan pada masa kehamilan. Kehamilan membutuhkan perhatian dari semua pihak terutama dalam keluarga khususnya suami (WHO, 2014).

Pemenuhan kebutuhan fisik dan psikologi selama kehamilan dapat terpenuhi jika peran suami istri dilakukan seiring sejalan. Berbagai kebutuhan fisiologi dalam masa kehamilan meliputi kebutuhan fisiologi selama kehamilan adalah kebutuhan nutrisi, eliminasi, istirahat tidur serta kebutuhan seksual. (Kemenkes RI, 2013). Kelangsungan kehamilan dari faktor ibu memegang peran penting untuk menjaga agar kehamilan tidak mengalami abortus. factor ibu baik riwayat penyakit yang didertia, riwayat abortus yang pernah dialami serta jumlah kehamilan yang pernah dirasakan dapat merupakan bagian kesiapan ibu dalam masa kehamilan (Darmawati, 2011; Katmini, 2020).

Peran bidan sangat penting dalam memberikan asuhan kebidanan pada masa kehamilan pemeriksaan secara lengkap baik fisik maupun pemeriksaan penunjnag serta pemberian penyuluhan kesehatan yang lengkap perlu dilakukan oleh bidan. (Mikrajab \& Rachmawati, 2016). Kebutuhan seksual jarang mendapatkan perhatian khusus dari suami maupun tenaga kesehatan. Kurangnya pengetahuan dan informasi tentang hubungan seksual selama kehamilan akan menyebabkan 
sering wanita kurang mendapatkan pemenuhan kebutuhan seks. Peran gender ada di masyarakat Jawa terutama menyebutkan bahwa wanita memiliki tugas unutk selalu menghormati dan tunduk kepada suami, segala keputusan adalah diambil oleh suami demikian juga dalam hubungan seksual. apabila tidak terjadi kesimbangan kebutuhan dapat berakhir dengan kekerasan dalam rumah tangga berhubungan dengan kebutuhan seks (Aisyaroh, 2016).

Menurut penelitian Nurmaningsih tahun 2017 di dapatkan bahwa dalam budaya yang ada di Jawa perihal seksual merupakan hal tabu untuk diperbincangkan dalam kehidupan sehari hari termasuk dalam keluarga. Sebagian besar tenaga kesehatan dan masyarakat masih merasa tabu untuk membahas tentang seksual. Peran gender dapat dilihat dari pengambil inisiatif untuk melakukan hubungan seksual . Dalam gender yang berlaku di budaya jawa pria adalah memegang peran Maskulin sehingga harus mengambil keputusan, inisitaif lebih dahulu yang disebut besar ditentukan oleh suami sebagai pengambil keputusan dan wanita harus mengikuti. Peran gender wanita feminism yang lembut menurut semua keinginan suami, sedangkan kebutuhan seksual merupakan kebutuhan pria dan wanita (Nurnaningsih, 2017).

Frekuensi melakukan hubungan seks dapat mempengaruhi kejadian abortus pada ibu hamil. Kejadian abortus di pengaruhi dengan frekuensi seksual disamping faktor maternal dan faktor noenatal yang dibawa oleh ibu selama hamil. Terutama usia ibu hamil status kesehatan dan kelainan dari anatomi dapat mempengaruhi keselamatan ibu hamil dalam melakukan hubungan seks (Asi, 2018). Dari survey awal didapatkan 6 dari
10 ibu hamil di Desa Curugsewu menyatakan jarang melakukan hubungan seksual selama kehamilan awal.

Kebutuhan seksual pada kehamilan awal perlu memerhatikan riwayat abortus ataupun kondisi ibu dan janin karena dapat menyebabkan abortus salam kehamilan ini. Namun secara gender yang berlaku di masyarakat, pengambil inisitiaf adalah suami sehingga kemungkinan terjadi kekerasan baik fisik maupun psikologis dapat terjadi. Tujuan awal pemenuhan kebutuhan dari hubungan seks untuk memberikan rasa nyaman pada ibu hamil dapat berlawanan hasilnya karena menyebabkan keguguran bila dilakukan sengan frekuensi sering pada kehamilan beresiko. Belum ada penelitian tentang peran gender dalam hubungan seksual pada wanita hamil. Penelitian ini memiliki tujuan untuk mengetahui hubungan peran gender dalam hubungan seks pada wanita hamil.

\section{METODE PENELITIAN}

Jenis penelitian ini adalah non eksperiment dengan pendekatan cross sectional, yaitu penelitian yang hanya melakukan identifikasi saat penelitian. Tempat penelitian adalah di praktik mandiri bidan di Desa Curugsewu Kecamatan Patean Kabupaten Kendal yang dilaksanakan pada bulan Januari s.d Maret 2020. Populasi dalam penelitian ini adalah seluruh ibu hamil diwilayah Desa Curugsewu berjumlah 98 orang ibu hamil. Pengambilan sampel dilakukan secara accidental sampling dengan kriteria ibu hamil kurang dari 20 minggu, tinggal serumah dengan suami yang melakukan pemeriksaan kehamilan, dan bersedia menjadi responden, didapatkan 30 orang responden. Instrument dalam penelitian ini menggunakan kuesioner tertutup 
dengan 12 pertanyaan yang dibagikan oleh bidan dan mahasiswa kebidanan yang praktik kepada ibu hamil setelah dilakukan persamaan persepsi dengan peneliti. Kuesioner dibagikan kepada ibu hamil untuk diisi pada saat melakukan pengumpulan data subyektif Pada tanggal 5 Januari sampai dengan 27 Februari 2020 analisa data, menggunakan statistik non parametrik yaitu pengujian Kendal tau-b, pengujian dilakukan menggunakan program computer dengan SPSS 20 for Window.

\section{HASIL PENELITIAN}

Analisis Univariat untuk mengetahui distribusi frekensi dari variable penelitian peran gender dalam hubungan seksual pada ibu hamil.

Tabel 1. Distribusi Frekuensi Responden berdasarkan Peran Gender

\begin{tabular}{lrc}
\hline Karakteristik & F & \% \\
\hline Suami & 18 & 60 \\
Istri & 6 & 20 \\
Bersama & 6 & 20 \\
\hline Total & $\mathbf{3 0}$ & $\mathbf{1 0 0}$ \\
\hline
\end{tabular}

Berdasarkan tabel 1 didapatkan hasil bahwa sebagian besar 18 responden (60 $\%)$ responden melakukan hubungan seksual dengan peran suami dan 6 responden (20\%) melakukan hubungan seks dengan peran istri dan bersama sama antara suami dan istri.

Tabel 2. Distribusi Frekuensi Responden Berdasarkan Frekuensi Hubungan Seks

\begin{tabular}{lcc}
\hline Karakteristik & F & \% \\
\hline Sering & 5 & 16,7 \\
Jarang & 6 & 20 \\
Tidak Pernah & 19 & 63,3 \\
\hline Total & $\mathbf{3 0}$ & $\mathbf{1 0 0}$ \\
\hline
\end{tabular}

Dari tabel 2 didapatkan sebanyak 19 orang $(63,3 \%)$ tidak melakukan hubungan seks, 6 orang $(20 \%)$ jarang melakukan hubungan seks dan serta hanya sedikit yang frekeunsi sering melakukan hubungan seks selama kehamilan sebanyak 5 responden(16,7\%). Hasil uji statistik Kendall tau dengan bantuan program spss didapatkan pengujian hypothesis dengan korelasi Kendall tau non parametrik,diperoleh harga korelasi coefiicient $-391 *$ dengan nilai signifikansi sebesar 0,022 .
Nilai signifikasi $<0,05$ maka hipotesis yang dapat ditarik adalah ada hubungan antara peran gender dengan frekuensi hubungan seks dengan arah hubungan berlawanan, artinya semakin tinggi peran gender maka akan dibarengi dengan semakin rendah frekuensi hubungan seks dan sebaliknya. Hubungan antara peran gender dengan frekuensi hubungan seks. Tingkat keeratan hubungan cukup dan arah hubungan berbalik antara peran dan hubungan seksual pada ibu hamil. 


\section{PEMBAHASAN}

Peran gender mempengaruhi keputusan dalam melakukan hubungan seksual. Keputusan keluarga dipengaruhi peran gender yang berlaku dalam keluarga. Sebagian besar peran suami dalam pengambil keputusan untuk melakukan hubungan seksual. Hal ini sejalan dengan budaya masyarakat Jawa yang menempatkan suami sebagai kepala keluarga yang harus maskulin tetap kuat dan menentukan semua keinginan.Namun kemajuan zaman dan peningkatan pengetahuan wanita hamil sehingga sebagian kecil wanita berani melaksanakan peran gender dalam melakukan hubungan seksual.

Penelitian Puspitawati menggambarkan teori tentang struktur fungsional dimasyarakat serta dalam kehidupan sosial secara total. Teori ini menggambarkan bahwa dalam kehidupan, berbagai dinamika dapat terjadi tetapi keseimbangan perlu di dapatkan terutama dalam keluarga baik peran suami maupun istri dalam kehidupan yang modern. Kecemasan dapat dirasakan oleh ibu selama masa kehamilan. Perubahan fisik perubahan hormonal dan perubahan mood seringkali menyebabkan kecemasan ibu bertambah sehingga pengertian perhatian dari suami sangat diperlukan. Kondisi cemas yang dialami ibu dapat berdampak dalam pemenuhan fisik emosi serta kesejahteraan janinnya (Retnowati, 2011).

Perkembangan zaman saat ini tidak secara langsung mempengaruhi peran wanita dalam kesetaran gender. Penelitian Harun AR (2015), didapatkan sebagaian wanita lebih merasakan nyaman untuk tinggal dirumah dan melaksanakan tugas secara domestik sehingga segala kegiatan yang bersifat publik akan dilakansakan oleh kaum pria, sehingga ketimpangan gender dapat terjadi karena pengambil keputusan.

Penelitian tentang faktor yang menyebabkan terjadinya abortus spontan banyak dipengaruhi dari usia gravida serta riwayat abortus sebelumnya. Wanita memiliki peluang mengalami abortus bila memiliki faktor tersebut (Purwaningrum \& Fibriana, 2017). Hasil penelitian ini menunjukan factor yang mempengaruhi frekuensi dari hubungan seksual adalah dari kelompok multi gravida, dimana pengetahuan dan pengalaman yang dialami pada kehamilan lalu memberikan perasaan nyaman ibu untuk melakukan hubungan seksual, namun masih adanya mitos dan kurangnya pengetahuan serta rendahnya sosial ekonomi mempengaruhi terdapat hubungan antara peran gender dengan frekeuensi hubungan seksual.

Pada wanita hamil sebagian memilih tidak melakukan hubungan seksual terutama pada trimester awal kehamilan dan umumnya pemenuhan kebutuhan seks sangat tergantung dari peran suami dalam menentukan untuk melakukan hubungan seks dalam masa kehamilan. Hal ini sesuai dengan penelitian Puspitawati bahwa sampai saat ini walaupun telah berada di masa moderisasi wanita tetap menempatkan diri sebagai kelompok yang mengikuti keinginan. Faktor determinan yang mempengaruhi wanita melakukan hubungan seks adalah pengalaman abortus yang dialami ibu menyebabkan ibu hamil untuk berhati - hati, dan memilih tidak melakukan hubungan seks pada kehamilan trimester awal sebagai bentuk proteksi terhadap janin yang sangat diharapkan (Yanti, 2018). Dalam penelitian ini tidak dilakukan intervensi sehingga hanya melihat fenomena yang ada. Penelitian ini belum meneliti tentang tentang posisi dan tingkat kecemasan ibu hamil dalam 
melakukan hubungan seksual sehubungan dengan peran gender.

\section{KESIMPULAN DAN SARAN}

Terdapat hubungan yang bermakna antara peran gender dengan frekuensi hubungan seks ibu hamil di PMB Curug Sewu Kecamatan Patean. Semakin tinggi peran gender maka akan dibarengi dengan semakin rendah frekuensi hubungan seks dan sebaliknya. Pemberian asuhan kebidaan antenatal care bidan, wajib memperhatikan dan memberikan penyuluhan kesehatan tentang hubungan seks dalam kehamilan dan kondisi ibu hamil yang tidak boleh melakukan hubungan seksual, terutama dengan riwayat abortus.

Bidan diharapkan dapat memotivasi agar suami berperan dengan adil dan komunikasi yang terbuka dalam memahami kebutuhan seksual selama kehamilan. Bagi ibu hamil diharapkan dapat lebih meningkatkan kemampuan dalam berkomunikasi serta menyampaikan keluhan selama kehamilan kepada suaminya. Peneliti selanjutnya dapat melakukan intervensi untuk meningkatkan peran wanita untuk memenuhi hak seksualnya dimasa kehamilan, sehingga dapat menentukan frekuensi seksual untuk mencegah terjadinya abortus dan ibu mendapatkan kepuasan.

\section{DAFTAR RUJUKAN}

Aisyaroh, N. (2016). Upaya Preventif Permasalahan Kesehatan Reproduksi Perempuan Lapas. Majalah Ilmiah Sultan Agung.

Asi, M. (2018). Hubungan Peran Gender Dengan Pengambilan Keputusan Pelayanan Kebidanan Menghadapi
Persalinan Pada Ibu Hamil

Trimester Iii Di Puskesmas Landono

Tahun 2018. Poltekkes Kemenkes Kendari.

Darmawati, D. (2011). Mengenali Abortus Dan Faktor Yang Berhubungan Dengan Kejadian Abortus. Idea Nursing Journal.

Harun Ar, M. Q. (2015). Rethinking Peran Perempuan Dalam Keluarga. Karsa: Jurnal Sosial Dan Budaya Keislaman. https://doi.org/10.19105/karsa.v23i1 .607

Katmini, K. (2020). Determinan Kesehatan Ibu Hamil Tentang Tanda Bahaya Kehamilan dengan Pencapaian Kontak Minimal 4 Kali Selama Masa Kehamilan (K4). Jurnal Kebidanan Dan Kesehatan Tradisional, 5(1), 29-35.

Kemenkes RI. (2013). Kehamilan, Persalinan, dan Nifas Normal. Buku Saku Pelayanan Kesehatan Ibu di Fasilitas Kesehatan Dasar Dan Rujukan.

https://doi.org/10.1016/j.mcna.2016. 06.004.Nutrition

Mikrajab, M. A., \& Rachmawati, T. (2016). Policy Analysis of Integrated Antenatal Care implementation at Public Health Centers in Blitar City. Buletin Penelitian Sistem Kesehatan. https://doi.org/10.22435/hsr.v19i1.4 988.41-53

Ningsih, Y. T. (2018). Pelatihan Pendidikan Seksual Untuk 
Meningkatkan Pengetahuan Tentang Seksualitas Anak Pada Guru Di Kab. Tanah Datar. Jurnal Rap (Riset Aktual Psikologi Universitas Negeri Padang).

https://doi.org/10.24036/rapun.v9i2. 102216

Nurnaningsih, -. (2017). Nilai Edukasi Metafora Teks-teks Seksual dalam Serat Centhini Karya Pakubuwana V. Jurnal IKADBUDI. https://doi.org/10.21831/ikadbudi.v5 i12.12311

Pudiastuti, R. (2012). Asuhan Kebidanan Pada Ibu Hamil Normal Dan Patologi. In Mulia Medika.

Purwaningrum, E. D., \& Fibriana, A. I. (2017). Faktor Risiko Kejadian Abortus Spontan. Higeia Jorunal Of Public Health.

Puspitawati, H. (2012). Gender dan keluarga: konsep dan realita di Indonesia. In $P T$ IPB Press. https://doi.org/10.1017/S003358350 1003705

Retnowati, S. (2011). Pengaruh Pelatihan Relaksasi Dengan Dzikir Untuk Mengatasi Kecemasan Ibu Hamil Pertama. Psikoislamika: Jurnal Psikologi Dan Psikologi Islam. https://doi.org/10.18860/psi.v0i1.15 43

WHO, 2014. (2014). Angka kematian ibu. Jurnal Ilmiah Kebidanan Indonesia. https://doi.org/10.33221/jiki.v10i01. 423
Yanti, L. (2018). Faktor determinan kejadian abortus pada ibu hamil: case control study. MEDISAINS. https://doi.org/10.30595/medisains.v 16i2.3002 